\title{
20 years managing malignant pleural mesothelioma: a review of our experience and the quest for the optimal prognostic marker
}

\section{0 anos de abordagem do mesotelioma pleural maligno: uma revisão da nossa experiência e a a procura pelo marcador prognóstico ideal}

\author{
João Nunes Caldeira",* (iD), Sofia Rodrigues Sousa ${ }^{1}$ (iD), Ana Maria Figueiredo ${ }^{1}$ (iD), Alice Pêgo ${ }^{1}$, Fernando Barata ${ }^{1}$ (iD \\ ${ }^{1}$ Serviço de Pneumologia do Centro Hospitalar e Universitário de Coimbra \\ * joaoncaldeira@gmail.com
}

\begin{abstract}
Introduction: Malignant pleural mesothelioma (MPM) is a rare, but aggressive incurable cancer. A variety of prognostic tools have been developed to guide clinicians and patients in the management of MPM regarding the most appropriate therapy and survival time.

Objectives: To evaluate the usefulness of the Brims' decision tree analysis, the EORTC prognostic score, the CALGB prognostic groups, the modified Glasgow Prognostic Score (mGPS), and the LENT prognostic score in our MPM patients.

Methods: Local retrospective database analysis of patients with MPM diagnosed between 2000 and 2020 . The different prognostic scores were applied and MPM group risks' evolution was analyzed. Statistical analysis was performed with IBM ${ }^{\circledR}$ SPSS $^{\circledR}$ Statistics 25.

Results: A total of 67 patients were evaluated (55 males, $82.1 \%$ ). Epithelioid MPM was the commonest histological type (51 patients, 76.1\%). Median overall survival (OS) was 11 months (IQR 23) and median progression free-survival (PFS) was 7 months (IQR 12.5). Survival distributions were statistically significantly different for the Brims' and the mGPS' groups (respectively, $X^{2}=7.188, p=.027$, and $X^{2}=6.46, p=.04$ ). For EORTC, CALGB and LENT score, there were not statistically significant differences in survival distributions (respectively, $X^{2}=.57, p=$ .811; $X^{2}=7.978, p=.157$; and $X^{2}=1.23, p=.267$ ). Brims' model and mGPS statistically significantly predicted OS (respectively, $F(1,57)=11.1, p<0.01$, and $F(1,32)=6.846, p=.01$ ). EORTC, CALGB and LENT failed to statistically significantly predict $\mathrm{OS}$ (respectively, $F(1,44)=.003, p=.955 ; F(1.43)=.722, p=0.4 ;$ and $F(1,14)=$ 1.193, $p=.293)$.

Conclusion: The small number of patients included and missing data for some parameters are limitations of our analysis. However, to our knowledge, this was the first study and the largest cohort to address MPM prognostic
\end{abstract}


scores in our country. In our cohort, the Brims' model and mGPS were useful in predicting survival. Both are simple tools with easily accessible parameters and should be considered for clinical practice.

Key-words: Mesothelioma, malignant, survival analysis, prognosis

(c) 2021 Grupo de Estudos do Cancro do Pulmão. Publicado por Publicações Ciência \& Vida. Este é um artigo Open Access sob uma licença CC BY-NC-ND (http://creativecommons.org/licenses/by-nc-nd/4.0/).

\section{RESUMO}

Introdução: O mesotelioma pleural maligno (MPM) é um cancro raro, mas agressivo e sem cura. Têm sido desenvolvidas diversas ferramentas na tentativa de ajudar os clínicos e os doentes na abordagem do MPM, particularmente no que concerne à escolha da terapêutica apropriada e à sobrevida.

Objetivos: Avaliar a utilidade da Brims' decision tree, do EORTC prognostic score, do CALGB prognostic groups, do modified Glasgow Prognostic Score (mGPS), e do LENT prognostic score nos nossos doentes com MPM.

Métodos: Foi conduzida uma análise retrospectiva de todos os doentes com MPM diagnosticados entre 2000 e 2020. Os diferentes scores de prognóstico foram aplicados, tendo-se avaliado a evolução da sobrevida em função dos diferentes grupos de risco para o MPM.

Resultados: Foram avaliados um total de 67 doentes (55 homens, 82,1\%). O MPM epitelióide foi o tipo histológico mais comum (51 doentes, 76,1\%). A sobrevida global mediana (OS) foi de 11 meses (IQR 23) e a sobrevida livre de progressão mediana (PFS) foi de 7 meses (IQR 12,5). A sobrevida foi diferente de modo estatisticamente significativo entre os grupos do modelo de Brims e do mGPS (respetivamente, $X^{2}=7.188, p=.027$, and $X^{2}=6.46, p=.04$ ). Para os scores EORTC, CALGB e LENT, não existiram diferenças estatisticamente significativas na distribuição da sobrevida (respetivamente, $X^{2}=.57, p=.811 ; X^{2}=7.978, p=.157$; e $X^{2}=1.23$, $p=.267$ ). O modelo de Brims e o mGPS previram a OS de modo estatisticamente significativo (respetivamente, $F(1,57)=11.1, p<0.01$, e $F(1,32)=6.846, p=.01)$. Os scores EORTC, CALGB e LENT não conseguiram prever de modo estatisticamente significativo a OS (respetivamente, $F(1,44)=.003, p=.955 ; F(1.43)=.722, p=$ 0.4 ; e $F(1,14)=1.193, p=.293$ ).

Conclusão: $O$ reduzido número de doentes e a inexistência de dados de alguns parâmetros são limitações da nossa análise. No entanto, do nosso conhecimento, este foi o primeiro estudo a abordar os diferentes scores de prognóstico do MPM no nosso país. Na nossa coorte, o modelo de Brims e o mGPS demonstraram-se úteis na previsão da sobrevida. Tratam-se de ferramentas simples, que incorporam parâmetros facilmente acessíveis, e que, por isso, sugere-se a sua consideração na a prática clínica.

Palavras-chave: Mesotelioma pleural maligno, sobrevida, prognóstico

(c) 2021 Grupo de Estudos do Cancro do Pulmão. Published by Publicações Ciência \& Vida. This is an open access article under the CC BY-NC-ND license (http://creativecommons.org/licenses/by-nc-nd/4.0/).

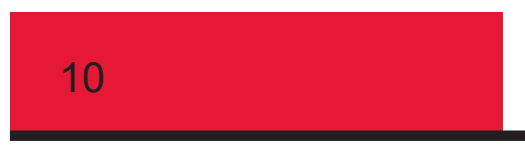




\section{INTRODUCTION}

Malignant Pleural Mesothelioma (MPM) is a rare, aggressive, and incurable cancer. It carries a very poor prognosis which is reflected in the median overall survival of (OS) of approximately 12 moonths ${ }^{1}$ and survival rates at 1 and 3 years of, respectively, $38 \%$ and $7 \% .^{2}$

MPM has limited therapeutic options. Surgery is only indicated for highly selected patients and in the context of clinical trials or multimodality treatment. The vast majority ends up receiving systemic therapy with platin-based chemotherapy plus pemetrexed ${ }^{1,2}$, although it has potential side effects and only a modest survival benefit. ${ }^{3}$

Given the scarcity of available therapeutic options, it would be advisable to carry out an individual assessment of risk or prognosis. Several features have been proposed as predictors of worse prognosis, such as performance status (PS), non-epithelioid histology, elevated platelet (PLT) and white blood cell (WBC) counts, neutrophil-to-lymphocyte ratio (NLR), platelet-to-lymphocyte ratio (PLR), or immunohistochemistry features. ${ }^{3-5} \mathrm{~A}$ variety of tools have also been developed in an attempt to facilitate prognostic stratification and best guide management. The application of these indexes is even recommended in the latest British Thoracic Society Guidelines for the investigation and treatment of malignant pleural mesothelioma. ${ }^{6}$ The proposed tools have different complexities and incorporate different clinical, laboratory, and histological parameters. Some are specific of MPM, namely the decision tree analysis (Brims' model $)^{7}$, and others are non-specific, namely the European Organization for Research and Treatment Cancer Prognostic Score $(E P S)^{8}$, the Cancer and Leukemia Group B score (CALGS) ${ }^{9}$, the modified Glasgow Prognostic Tool (mGPS) ${ }^{10,11}$ or, in individuals with malig- nant pleural effusion (MPE), and the Lactate dehydrogenase $[\mathrm{LDH}]$ pleural fluid $(\mathrm{L})$, Eastern Cooperative Oncology Group PS (E), NLR (N) and tumor type $(T)-$ LENT $_{\text {score }}{ }^{12}$. Through its application, patients are divided into different groups, with a greater or lesser risk of an unfavorable prognosis:

- The Brims model incorporates clinical (weight loss, PS), histological, and laboratory (hemoglobin, albumin) findings to classifie patients in 4 groups ( 1 to 4 , the lowest with the best prognosis) ${ }^{7}$;

- EPS uses patient's age and PS, presence and subtype of histologic diagnosis, and WBC count at presentation to categorize patients in favorable or unfavorable prognosis groups ${ }^{8}$;

- CALGBS incorporates the presence of non-epithelioid histology, weight loss or chest pain, high PLT and WBC count, low hemoglobin, high serum LDH, advanced age, and PS, and categorizes patients in 6 groups (groups 1 to 6 , the lowest with the best prognosis);

- mGPS takes into account albumin and hemoglobin levels, and divides patients into 3 groups $(0,1$, and 2 , the lowest with the best prognosis) ${ }^{10,11}$;

- LENT score classifies patients into low, moderate, and high-risk groups. ${ }^{12}$

Particular emphasis is given to the decision tree analysis in published guidelines. ${ }^{6,13}$ Our study aims to review our experience in the management of MPM, to investigate possible prognostic markers for MPM, and to assess the usefulness of the Brims model and, as a secondary analysis, of the other proposed prognostic scores (EPS, CALGBS, mGPS and LENT score) in our patients with MPM. 


\section{METHODS}

\section{Study population}

We retrospectively selected adult patients with MPM between January 2000 to December 2020 followed at the Centro Hospitalar e Universitário de Coimbra (CHUC). Informed consent was waived because of the retrospective design of the study and the high mortality rate.

\section{Data collection}

We collected clinical, demographic, laboratory, radiological, and histological data, regarding age, gender, ECOG PS, survival, hemoglobin, white blood cell and platelet count, serum albumin and LDH levels, pleural fluid LDH, and biopsy result. OS was considered from the date of diagnosis of MPE until the date of death or the date of the last hospital visit. Progression-free survival (PFS) was defined as the time elapsed between treatment initiation and the date progression was observed. The Brims' decision tree, the EPS, the CALGBS, the mGPS, and the LENT score were applied according to the published literature and MPM group risks' evolution was analyzed.

\section{Statistical analysis}

Statistical analysis was performed with IBM ${ }^{\circledR}$ SPSS $^{\circledR} 25$. Continuous variables are presented as median and interquartile range (IQR) or mean and standard deviation (SD) whenever had normal or non-normal distribution, respectively. Categorical variables are presented as numbers. Qualitative data are described using relative frequencies. As OS was a variable with non-normal distribution, between groups comparison was performed with the Mann-Whitney $U$ or the Kruskal-Wallis $\mathrm{H}$ test whenever groups had two or more levels, respectively. Kaplan-Meier survival analysis was conducted to compare survival dis- tributions between treatment modalities or the scores different MPM group risks and the log-rank test to determine if there were differences in the survival distributions. Whenever there were differences, pairwise log-rank comparisons were conducted to determine which groups had different survival distributions. The Spearman's rank-order correlation was run to assess the strength and direction of the association/relationship between continuous variables. Linear regression was run to understand the effect of the different MPM group risks on OS (i.e. if the scores could predict survival). A $p$-value less than 0.05 was considered statistically significant.

\section{RESULTS}

\section{Baseline characteristics}

Table 1 shows the sample characteristics. A total of 67 patients were enrolled in our study. Most were males $(n=55 ; 82.1 \%)$ and mean age at diagnosis was 67.5-year-old ( \pm 11.5$)$. Smoking habits, either active or former smoker, were present in 35 individuals (52.3\%). Asbestos exposure was found in 26 patients (38.8\%). Median OS was 11 months (IQR 23) and median PFS was 7 months (IQR 12.5).

Epithelioid MPM was the commonest histological type ( $n=51 ; 76.1 \%)$, followed by sarcomatoid $(n=10 ; 14.9 \%)$ and biphasic $(n=6 ; 9 \%)$ histology. OS and PFS were not statistically significantly different between the different histological subtypes, repectively, $X^{2}(2)=1.077, p=.583$ and $X^{2}(2)=.523 p=.77$.

\section{Treatment modality}

Chemotherapy (ChT) was used as the 1st-line modality treatment in the majority of patients $(n=$ $47 ; 71.2 \%$ ). A platinum plus pemetrexed was the 
Table 1. Sample characteristics

\begin{tabular}{|l|c|c|}
\hline Age at diagnosis (years) $^{*}$ & 67.5 & $(11.5)$ \\
\hline Gender, $\mathbf{n}$ (\%) & & \\
Male & 55 & $(82.1)$ \\
Female & 12 & $(17.9)$ \\
\hline Smoking habits, $\mathbf{n}$ (\%) & & \\
Active smoker & 16 & $(23.9)$ \\
Former smoker & 19 & $(28.4)$ \\
Non-smoker & 29 & $(43.3)$ \\
Unknown & 3 & $(4.5)$ \\
\hline Asbestos exposure, $\mathbf{n}$ (\%) & & \\
With asbestos exposure & 26 & $(38.6)$ \\
Without asbestos exposure & 25 & $(37.3)$ \\
Unknown & 16 & $(23.9)$ \\
\hline Overall survival (OS) [months] $^{*}$ & 11 & $(23)$ \\
\hline Progression-free survival (PFS) [months] $^{*}$ & 7 & $(12.5)$ \\
\hline
\end{tabular}

* Mean (SD) or median (IQR) were used whenever variables followed a normal or non-normal distribution, respectively.

preferred regimen ( $n=31 ; 53.5 \%$ ). Radical surgery alone was employed in 2 patients (3\%), a combined surgery plus ChT modality in 10 $(15.2 \%)$, and best supportive care (BST) in 7 (10.4\%). Median OS (IQR) was 64,5 (-), 11 $(12,25), 28,5(37,75)$ and $2(3,5)$ months for, respectively, surgery alone, ChT alone, surgery plus ChT or BST. OS was statistically significantly different between the different treatment modalities, $X^{2}(3)=15.716, p<0.01$. Patients that underwent surgery (either alone or in multimodality regimen with $\mathrm{ChT}$ ) had a median estimated OS of 28.0 $(95 \% \mathrm{Cl}, 1.66$ to 54.3$)$ months, which was longer than the other treatments. The survival distributions for the interventions were statistically significantly different, $X^{2}(3)=30.999, p<.001$.

\section{Prognostic factors}

Table 2 shows different laboratory findings at diagnosis and Table 3 displays the differences in median OS for some proposed prognostic markers in the literature. Median NLR was 4.13 (IQR
Table 2. Laboratory findings at diagnosis*

\begin{tabular}{|l|c|c|}
\hline Hemoglobin $(\mathrm{g} / \mathrm{dL})$ & 12.42 & $(2.05)$ \\
\hline Leucocytes $\left(\times 10^{9} / \mathrm{L}\right)$ & 9.57 & $(5.02)$ \\
\hline Neutrophils $\left(\times 10^{9} / \mathrm{L}\right)$ & 6.6 & $(2.64)$ \\
\hline Lymphocytes (x109/L) & 1.52 & $(0.92)$ \\
\hline Platelets (x10 $/ \mathrm{L})$ & 357 & $(188)$ \\
\hline Serum lactate dehydrogenase (LDH) (U/L) & 288 & $(151.5)$ \\
\hline Pleural LDH (U/L) & 942 & $(953.67)$ \\
\hline Serum albumin (g/dL) & 3.5 & $(0.67)$ \\
\hline C reactive protein (mg/dL) & 7.14 & $(7.24)$ \\
\hline Neutrophil-to-lymphocyte ratio (NLR) & 4.13 & $(2.71)$ \\
\hline Platelet-to-lymphocyte ratio (PLR) & 255 & $(167)$ \\
\hline
\end{tabular}

* Mean (SD) or median (IQR) were used whenever variables followed a normal or non-normal distribution, respectively.

2.71) and PLR was 255 (IQR 167). There was a no statistically significant small negative correlation between NLR and OS and PLR and OS (respectively $r_{s}(65)=-.075, p=.644$ and $r_{s}(65)=-.104$, $p=.523)$. Median OS was not statistically significantly different between LDH, PLT, and NLR cut-off values of $500 \mathrm{U} / \mathrm{L}, 400 \times 109 / \mathrm{L}$ and 5 , respectively, and males and females, respectively $U$ $=56.5, z=-1.45, p=.260 ; U=287.5, z=.597, p$ $=.550 ; U=196.5, z=1.122, p=.267$; and $U=$ 289.0, $z=.054, p=.957$.

Table 3. Differences in OS (months) for some proposed prognostic factors in the literature

\begin{tabular}{|l|c|c|c|}
\hline & Median & IQR & $p$-value \\
\hline Non-epithelioid histology & 7 & $(25)$ & .583 \\
\hline Platelets $>400 \times 10 \% / L$ & 9 & $(10.75)$ & .55 \\
\hline NLR $>5$ & 7 & $(30)$ & .267 \\
\hline Serum LDH > 500 U/L & 30 & $(64)$ & .26 \\
\hline Male gender & 11 & $(19.5)$ & .957 \\
\hline
\end{tabular}


Table 4. Characterization of Brims' decision tree groups*

\begin{tabular}{|l|c|c|c|c|c|c|}
\hline & $\mathbf{n}$ & $(\%)$ & \multicolumn{2}{|c|}{ Age at diagnosis** } & \multicolumn{2}{|c|}{ OS $^{* *}$} \\
\hline Group 2 & 10 & $(15,9)$ & 62 & $(12,6)$ & 39 & $(57)$ \\
\hline Group 3 & 22 & $(34,9)$ & 66 & $(11,1)$ & 14 & $(21,5)$ \\
\hline Group 4 & 31 & $(49,2)$ & 71 & $(10,9)$ & 14 & $(15,5)$ \\
\hline
\end{tabular}

* In 4 patients there was insufficient data to classify them. ${ }^{* \star}$ Mean (and SD) or median (and IQR) were used whenever variables followed a normal or non-normal distribution.

\section{Prognostic tools}

a) Brims decision tree

Brims' MPM group risks were as follow: group 2, 10 patients (15.9\%); group 3, 22 (34.9\%); and group 4, 31 (49.2). There were insufficient data to characterize 4 patients. Table 4 displays a summary characterization of the Brims' MPM risk groups. OS were statistically significantly different between the different Brims model groups, $X^{2}(2)$ $=7.732, p=.021$ Patients of group 2 had an estimated OS of 46 months $(95 \% \mathrm{Cl}, 14.278$ to
77.722). This was longer than the OS of group 3 or group 4 which had identical median time to death of $14.00(95 \% \mathrm{Cl}, 7.333$ to 20.667$)$ months and 8 ( $95 \% \mathrm{Cl}, 5.772$ to 10.228$)$ months, respectively. The survival distributions for the 3 groups were statistically significantly different, $X^{2}(2)=$ $7.188, p=.027$ - Figure 1. There was a statistically significant difference in survival distributions for group 2 vs group $3, X^{2}=5.193, p=.019$, and group 2 vs group $4, X^{2}=6.018, p=.014$. However, the survival distributions for groups 3 and 4 were not statistically significantly different, $X^{2}=.266, p$ $=.606$. Brims' model statistically significantly predicted OS $(F(1,57)=11.1, p<.01)$.

\section{b) Other scores}

Prognostic groups in the EPS were: good prognosis, 30 patients $(62.5 \%)$, and poor prognosis, 18 $(37.5 \%)$. There was insufficient data to characterize 19 patients in this score. Median OS was not statistically significantly different between EPS

Figure 1. Kaplan-Meier survival curves for Brims decision tree prognostic groups

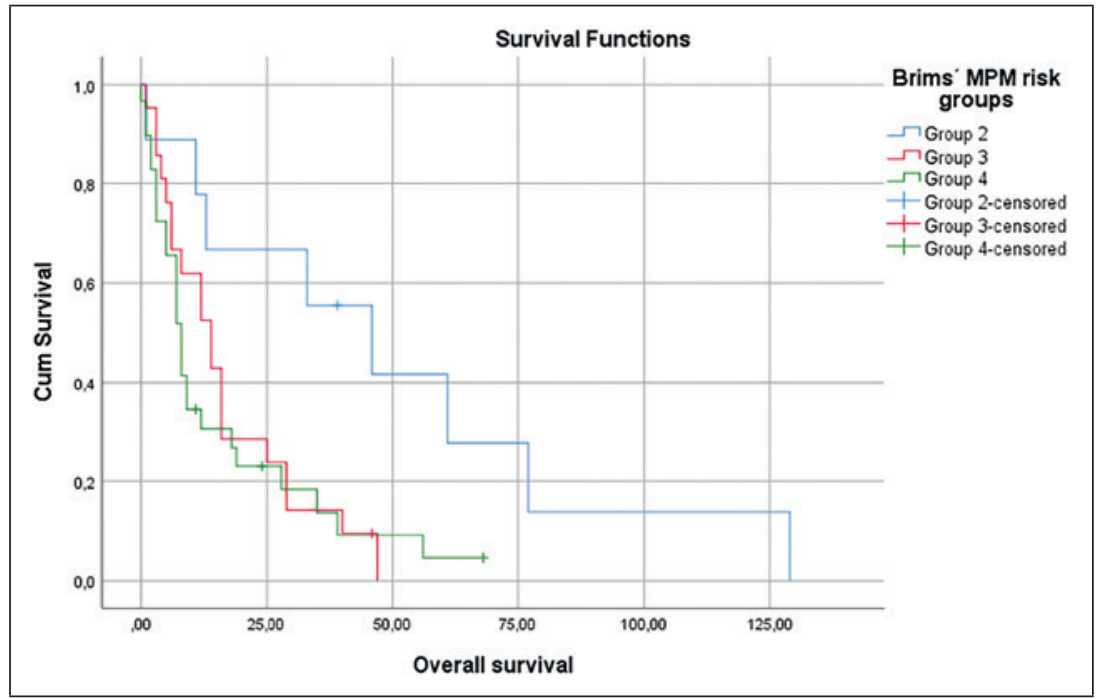


groups, respectively $U=264.5, z=.566, p=.572$ ). The survival distributions were not statistically different $\left(X^{2}=.057, p=.811\right)$ between groups.

CALGBS prognostic groups were as follow: group 1, 1 patient (2.2\%); group 2, $3(6.5 \%)$; group 3, 16 (34.8\%); group 4, 4 (8.7\%); group 5, 17 (37\%); and group 6, 6 (10.9\%). Median OS was not statistically significantly different between CALGBS groups, $\left.X^{2}(5)=10.805, p=.055\right)$. The survival distributions were not statistically different $\left(X^{2}=7.978, p=.157\right)$ between groups.

In regards to mGPS, prognostic groups were as follows: group 0, 8 patients $(22.2 \%)$; group 1 , 17 (47.2\%); and group 2, 11 (30.6\%). There was insufficient data to characterize 31 patients in this score. OS was statistically significantly different between mGPS groups, $X^{2}(2)=6.145, p=.046$. Patients of mGPS group 0 had an estimated OS of $46(95 \% \mathrm{Cl}, 28.319$ to 63.681$)$ months, which was longer than for groups 1 and 2, respectively, 9 (95\% Cl, 2.277 to 15.723$)$ months; and 7 (95\% $\mathrm{Cl}, 4.078$ to 9.922$)$ months. The survival distributions for the mGPS groups were statistically significantly different, $X^{2}(2)=6.46, p=.04$. There was a statistically significant difference in survival distributions for group 0 vs group $1, X^{2}=4.183, p=$ .041 , and group 0 vs group $2, X^{2}=6.650, p=.01$. However, the survival distributions for groups 1 and 2 were not statistically significantly different, $X^{2}=.687, p=.407$.

LENT score incorporated 3 group risks, being: low risk, 7 patients $(41.2 \%)$; intermediate, 9 (52.2\%); high, 1 (5.9\%). There was insufficient data to characterize 17 patients in this score. OS was not statistically significantly different between groups, $\left.X^{2}(3)=9.756, p=.185\right)$. The survival distributions were not statistically different $\left(X^{2}=\right.$ 1.23, $p=.267$ ).

mGPS statistically significantly predicted OS $(F(1,32)=6.846, p=.01)$. EPS, CALGBS and
LENT failed to statistically significantly predict OS (respectively, $F(1,44)=.003, p=.955 ; F(1.43)=$ $.722, p=.4$; and $F(1,14)=1.193, p=.293)$.

\section{DISCUSSION}

Mesothelioma is an aggressive cancer with limited therapeutic options. In our population, it was more common in males, the epithelioid subtype was more prevalent, the age at diagnosis was 67.5 years and survival was around one year, which is in line with what is described in the literature..$^{1,2}$

Regarding our country, the epidemiology of MPM is still scarce. ${ }^{14}$ Concerning the baseline characteristics of the population, our data is in line with a recent study carried out by Baptista et al. ${ }^{15}$ Greater investment in research in this area could help to better understand the profile of mesothelioma patients in Portugal and check for regional differences.

Asbestos exposure was described in $38.6 \%$ of patients, which turns out to be a small percentage given it was similar to non-exposure (37.3\%). In 16 individuals (23.9\%) there was no reference to asbestos, and as so exposure may be underestimated. It is well-known that documenting and quantifying asbestos exposure can be difficult: it may not be recalled or recalled erroneously or by the possibility of compensatory damages; the level and type of exposure may be different in the same workplace; and nonoccupational exposure may also have a role. ${ }^{2}$

Platinum-based chemotherapy in combination with pemetrexed was the treatment of choice in most patients with advanced disease, according to existing guidelines. ${ }^{6,13,16}$ It yields the highest tumor response rates but has potential side effects and only modest survival. ${ }^{3}$ In our cohort, patients treated with surgery (alone or with $\mathrm{ChT}$ ) had lon- 
ger OS compared to other regimens BST, probably referable to a lower staging at diagnosis and better fitness of the patients. This emphasizes the urge to better predict the prognosis for better management of our patients, in a case-by-case risk-benefit assessment.

Some clinical, analytical, histological, and immunohistochemical features have been proposed as prognostic factors ${ }^{3-5}$ and we tested some. Contrary to expected, OS did not statistically differ between patients regarding LDH, PLT, and NLR cut-off values of $500 \mathrm{UL}-1,400 \times 109 / \mathrm{L}$ and 5 , respectively, and between gender. NLR and PLR also had a no statistically significant negative correlation with OS. There remain some questions on the usefulness of these parameters. For example, as with other malignancies, inflammation may play a role in MPM carcinogenesis and inflammatory markers, such as NLR and PLR are proposed to predict a worse outcome. However, although the NLR is more or less consensual and may even be associated with the histological subtype of $\mathrm{MPM}^{3,4,17}$, there are still controversies regarding its real value ${ }^{18}$ and the ideal cutoff point, which has varied in studies. ${ }^{4}$ On the other hand, the usefulness of the PLR does not seem to be relevant. ${ }^{3}$

The use of prognostic tools has recently gained interest and is recommended in guidelines. ${ }^{6}$ This topic, especially the Brims decision tree, has already been evaluated in our country with similar results to ours..$^{15}$ However, to our knowledge, an assessment of the different prognostic scores has never been performed in our country. In our study, survival distributions were statistically significantly different for the Brims' and the mGPS' groups, and these scores statistically significantly predicted OS. The differences in OS between Brims' groups 3 and 4, and mGPS groups 1 and 3 were not statistically significant, which raises some questions on potential limitations of these tools. Nevertheless, these are validated and simple tools with easily accessible parameters that can be used in daily practice. ${ }^{3,7}$ Probably the small number of patients influenced our results and newer studies with larger populations will give more robust conclusions. For EPS, CALGBS and LENT score, there were not statistically significant differences in survival distributions, and these scores failed to statistically significantly predict OS. These scores should be used with precaution. EPS and CALGBS are complex indexes and despite having generated some scientific interest in the past, they are rarely used outside the context of clinical trials. ${ }^{3,19}$ As for the LENT score, it is validated not only for MPM but for other cancers $^{12}$, and its use is relatively simple. Our results were surprising, but probably the missing data had some influence. Larger and better-designed studies could give us more insights. Finally, none of these scores take treatment options into account. As treatment modality can influence OS, prognostic scores that incorporate treatment regimen could be valuable. Thus, the use of such scores, such as the one developed recently by Katakoa et al. ${ }^{19}$, should deserve some interest.

Our study had some limitations. The small sample, the retrospective design, and the existence of missing data are limitations of the analysis. However, it encompasses an assessment of the different scores and, as mentioned, it is the first study to do so in our country.

\section{CONCLUSIONS}

In our cohort, median OS was inferior to 1 year. Treatment modality including surgery seemed to be related to longer OS, probably referable to a lower staging at diagnosis and better fitness of the patients. The Brims' model and mGPS were useful 
in predicting survival. Both are simple tools with easily accessible parameters and should be considered for clinical practice. As the Brims' model takes into account clinical, histological and laboratory parameters and the mGPS considers only laboratory findings, we believe that the Brim decision tree should deserve a preferential approach.

\section{ORCID}

\author{
João Nunes Caldeira (iD 0000-0001-7949-1946 \\ Sofia Rodrigues Sousa (iD) 0000-0001-8043-3874 \\ Ana Maria Figueiredo (iD) 0000-0002-7949-8440 \\ Fernando Barata (iD 0000-0002-6306-0938
}

\section{REFERENCES}

1. Kim RY, Sterman DH, Haas AR. Malignant Mesothelioma: Has Anything Changed? Semin Respir Crit Care Med. 2019;40(3):347-360.

2. Asciak R, George V, Rahman NM. Update on biology and management of mesothelioma. Eur Respir Rev. 2021;30(159):1-13.

3. Pinato DJ, Mauri FA, Ramakrishnan R, Wahab L, Lloyd T, Sharma R. Inflammation-based prognostic indices in malignant pleural mesothelioma. $J$ Thorac Oncol. 2012;7(3):587-594.

4. Brims FJH, Maskell NA. Prognostic factors for malignant pleural mesothelioma. Curr Respir Care Rep. 2013;2:100-108.

5. Motta AB, Pinheiro G, Antonângelo L, et al. Marcadores morfológicos de prognóstico no mesotelioma maligno: um estudo de 58 casos. J Bras Pneumol. 2006;32(4):322-332.

6. Woolhouse I, Bishop L, Darlison L, et al. British Thoracic Society Guideline for the investigation and management of malignant pleural mesothelioma. Thorax. 2018;73(March):i1-i30.

7. Brims FJH, Meniawy TM, Duffus I, et al. A novel clinical prediction model for prognosis in malignant pleural mesothelioma using decision tree analysis. J Thorac Oncol. 2016;11(4):573-582.
8. Curran BD, Sahmoud T, Therasse P, Meerbeeck J Van, Postmus PE, Giaccone G. Prognostic Factors in Patients With Pleural Mesothelioma: The European Organization for Research and Treatment of Cancer Experience. J Clin Oncol. 1998;16(1):145-152.

9. Herndon JE, Green MR, Chahinian AP, Corson JM, Suzuki Y, Vogelzang NJ. Factors predictive of survival among 337 patients with mesothelioma treated between 1984 and 1994 by the Cancer and Leukemia Group B. Chest. 1998;113(3):723-731.

10. McMillan DC. An inflammation-based prognostic score and its role in the nutrition-based management of patients with cancer. Proc Nutr Soc. 2008;67(3):257-262.

11. Proctor MJ, Morrison DS, Talwar D, et al. An inflammation-based prognostic score (mGPS) predicts cancer survival independent of tumour site: A Glasgow Inflammation Outcome Study. $\mathrm{Br} J$ Cancer. 2011;104(4):726-734.

12. Clive AO, Kahan BC, Hooper CE, et al. Predicting survival in malignant pleural effusion: development and validation of the LENT prognostic score. Thorax. 2014;69:1098-1104.

13. Scherpereel A, Opitz I, Berghmans T, et al. ERS / ESTS / EACTS / ESTRO guidelines for the management of malignant pleural mesothelioma. Eur Respir J. 2020;55(6):1900953.

14. Fernandes A. Epidemiologia do mesotelioma. Revista GECP. 2015;XII(2):25-30.

15. Baptista M, Fernandes $G$, Magalhães $A$, et al. Mesotelioma pleural maligno: casuística de 20 anos. Pulmonology. 2020;26((Esp Cong 1)):5-59.

16. Baas P, Fennell D, Kerr KM, van Schil PE, Haas RL, Peters S. Malignant pleural mesothelioma: ESMO Clinical Practice Guidelines for diagnosis, treatment and follow-up. Ann Oncol. 2015;26(July):v31-v39.

17. Chen N, Liu S, Huang L, et al. Prognostic significance of neutrophil-to-lymphocyte ratio in patients with malignant pleural mesothelioma: A meta-analysis. Oncotarget. 2017;8(34):57460-57469.

18. Meniawy TM, Creaney J, Lake RA, Nowak AK. Existing models, but not neutrophil-to-lymphocyte ratio, are prognostic in malignant mesothelioma. Br J Cancer. 2013;109(7):1813-1820.

19. Kataoka Y, Yamamoto Y, Otsuki T, et al. A new prognostic index for overall survival in malignant pleural mesothelioma: The rPHS (regimen, PS, histology or stage) index. Jpn J Clin Oncol. 2015;45(6):562-568. 